\title{
Optimal Characteristics Calculation of the Air Chemical Regeneration System of Sealed Habitable Objects
}

\author{
E.I. Akulinin*, O.O. Golubyatnikov, D.S. Dvoretsky, S.I. Dvoretsky \\ Tambov State Technical University, 106, Sovetskaya ul., Tambov, 392000, Russia \\ *Corresponding author: Tel.: +7 90923140 61. E-mail: akulinin-2006@yandex.ru
}

\begin{abstract}
Using the developed mathematical model of a flow-type chemisorption reactor and RPK-P regenerative product (nanocrystalline potassium superperoxide attached to the fibers and pore surfaces of the fibrous polymer matrix), a series of computational experiments was carried out to study the effect of the load (the number of people in the shelter, their breathing patterns) and design parameters of a chemisorption reactor for the duration of the protective action of the life support system of people. The problem of calculating the optimal design parameters of a chemical air regeneration system that provides the composition of the atmosphere for oxygen and carbon dioxide in an airtight inhabited facility at a level comfortable for human breathing for a guaranteed time in the presence of uncertain ("inaccurate") information about the respiratory load and heat generation of people located in a sealed facility is formulated. An algorithm for solving it has been developed.
\end{abstract}

\section{Keywords}

Hermetic inhabited object; chemical air regeneration system; potassium superoxide; chemisorptions; oxygen; carbon dioxide; optimization; uncertainties; protective action time.

(C) E.I. Akulinin, O.O. Golubyatnikov, D.S. Dvoretsky, S.I. Dvoretsky, 2020

\section{Introduction}

In recent decades, active scientific research has been carried out on the creation of promising air regeneration systems for pressurized habitable objects (PHOs), while chemical air regeneration systems based on potassium superoxide are most widely used in Russia and abroad [1-12].

Regenerative products are formed in one form or another (granules, tablets, plates, perforated blocks, etc.), depending on operating conditions and design features of the air regeneration system. Thus, the RPK-P regenerative product developed at Roskhimzashita Corporation OJSC [12] is a plate made of a fibrous polymer matrix 3-5 $\mathrm{mm}$ thick, on the fibers and pore surfaces of which potassium superoxide crystals are fixed. The plate-shaped product is characterized by a highly developed mass transfer surface and a high porosity of $\sim 0.93$, which compares favorably with block products with a porosity of $\sim 0.5-0.6$.

Most of the existing hardware options for chemical air regeneration systems use a combined scheme that provides simultaneous absorption of carbon dioxide and oxygen evolution [1-11, 13-23]. The extraction of carbon dioxide from the gas-breathing mixture is carried out in a chemisorption reactor due to the chemical interaction (topochemical reaction) of potassium superoxide with $\mathrm{CO}_{2}$ in the presence of water vapor, which occurs on the solid surface of the chemisorbent with the participation of solids $\left(\mathrm{KO}_{2}\right.$ crystals), gases $\left(\mathrm{CO}_{2}, \mathrm{O}_{2}\right)$ and liquids $\left(\mathrm{H}_{2} \mathrm{O}, \mathrm{KOH}\right)$ [24].

When setting the task of calculating the optimal characteristics of a chemical air regeneration system, it is necessary to select a target function (optimality criterion), optimization parameters, restrictions on the quality and effectiveness of its functioning, determine the set of acceptable operating modes and develop an algorithm for calculating the optimality criterion and restriction functions using equations of a mathematical dynamics model functioning of the system.

The analysis of literary sources, theoretical and experimental studies showed that it is not possible to accurately determine (assign) a part of the initial data for designing a system of chemical air regeneration. 
Thus, in [25-38], the values of a person's respiratory load are used as inaccurate parameters, the values $g_{\text {ind }}^{\mathrm{O}_{2}}$, $g_{\text {ind }}^{\mathrm{CO}_{2}}$ which can change at certain intervals during the functioning of the regeneration system. In $[26,30]$, inaccurate parameters also include the total heat loss $Q_{\Sigma}$; in [26, 28, 30-32] - air temperature; in [32] - air pressure and humidity. The presence of inaccurate parameters indirectly has a noticeable effect on the quality of the chemical air regeneration system, characterized by known technological and technical and economic indicators, for example, the time of the protective action of the system, the cost of air regeneration, etc. The values of a person's respiratory load for oxygen and carbon dioxide and the total heat released by people and devices of the chemical air regeneration system can unpredictably change depending on the breathing mode (normal, excitement or light load, stressful). The quantitative accounting of a number of these "inaccurate" / random factors is the essence of the optimal design of a system for chemical air regeneration under conditions of partial (incomplete) uncertainty.

The aim of this work is to formulate and study the problem of optimizing the design parameters of a chemisorption reactor, in which a favorable atmosphere is provided for the life of people in the PHO for a guaranteed time of protective action under conditions of uncertainty of "inaccuracy" in the values of the respiratory load (for oxygen and carbon dioxide) and the total heat release of people and equipment in a PHO; development of an algorithm for its solution.

\section{The study of characteristics of the chemical air regeneration system}

The process of chemical regeneration of air is carried out in a flow-through reactor with a regenerative product in the form of plates, which are made of a highly porous glass fiber matrix with $\mathrm{KO}_{2}$ nanocrystals deposited on its fibers and pore surface. The pressurized habitable object is divided into three zones: I: the zone of exit of the gas-breathing mixture from the reactor; II: the vital area of people hiding in the facility; III: the zone of entry of the gas-breathing mixture into the reactor.

The volume of the regenerative product placed on one side of the plate is determined by the width $b$, height $l$ and layer thickness $\gamma$ : $V_{\text {layer }}=b \times l \times \gamma$. The reactor operates in forced ventilation mode.

Let the dynamics of functioning of the designed life support system be described by a vector nonlinear operator [24]:

$$
\mathbf{f}\left(x, d, y, y_{t}, y_{x}, a\right)=0,
$$

where $x=\left\{x_{j}, j=\overline{1, m}\right\} \in X$ is the vector of input coordinates $\left(V_{\mathrm{ob}}\right.$ is the volume of the pressurized habitable object, $\mathrm{m} ; n$ is the number of people sheltering, people; $c_{\mathrm{CO}_{2}}^{\text {in }}, c_{\mathrm{O}_{2}}^{\text {in }}, c_{\mathrm{H}_{2} \mathrm{O}}^{\text {in }}$ the concentration of carbon dioxide, oxygen and water at the inlet of the reactor, $\mathrm{mol} / \mathrm{m}^{3} ; g_{\mathrm{O}_{2}}, g_{\mathrm{CO}_{2}}$ the respiratory load created by a person with oxygen and carbon dioxide, respectively, $\mathrm{mol} / \mathrm{s} ; T_{\mathrm{g}}^{\text {in }}$ is temperature of the gas-air mixture at the reactor inlet, $\mathrm{K} ; W_{1}, W_{2}$ - chemical reaction rates of carbon dioxide absorption and oxygen evolution, $\mathrm{mol} /\left(\mathrm{m}^{3} \cdot \mathrm{s}\right) ; Q_{\Sigma}$ is total heat release in a pressurized habitable object, W; $G^{\text {in }}$ is the volumetric flow rate of the gas-air mixture provided by the fan at the inlet to the reactor, $\left.\mathrm{m}^{3} / \mathrm{s}\right) ; X$ is a bounded closed set from a number space $E^{m}$;

$y(x, t)=\left\{y_{i}(x, t), i=\overline{1, n}\right\} \in Y$ vector-function of the object's output coordinates $c_{\mathrm{CO}_{2}}(z, t), c_{\mathrm{O}_{2}}(z, t)$, $c_{\mathrm{H}_{2} \mathrm{O}}(z, t)$ concentration of carbon dioxide, oxygen and water in the gas phase, distributed over the height $z$ of the reactor plates, $\mathrm{mol} / \mathrm{m}^{3} ; \quad \bar{c}_{\mathrm{CO}_{2}}, \bar{c}_{\mathrm{O}_{2}}, \bar{c}_{\mathrm{H}_{2} \mathrm{O}}$ concentration of carbon dioxide, oxygen and water in the air of an airtight object, $\mathrm{mol} / \mathrm{m}^{3} ; a_{\mathrm{KO}_{2}}, a_{\mathrm{KOH}}$ concentration of substances $\mathrm{KO}_{2}$ and $\mathrm{KOH}$ in a regenerative product, distributed over the height $z$ of the reactor plates, $\mathrm{mol} / \mathrm{m}^{3} ; \bar{T}_{\mathrm{g}}$ is temperatures of the gas-air mixture and chemisorbent, distributed over the height $z$ of the plates with the regenerative product, $\mathrm{K}$; air temperature in a sealed inhabited object, K); $y_{t}, y_{x}$ partial derivatives of the output coordinates $y(x, t)$;

$$
\begin{aligned}
Y= & \left\{y(x, t): y^{-} \leq y(x, t) \leq y^{+}\right\} ; \\
& d=\left\{d_{j}, j=\overline{1, r}\right\} \in D \text { vector of design parameters }
\end{aligned}
$$

from a closed set $D \in E^{r}$ ( $b, l, \gamma$ width, height and depth of the layer of the regenerative product on one side of the plate, respectively, $\mathrm{m} ; \delta$ is the distance between the plates, $\mathrm{m} ; N$ is the number of plates with the regenerative product, pcs.);

$$
a=\left\{a_{\rho}, \rho=\overline{1, r}\right\} \text { is vector of physicochemical }
$$

parameters from a limited closed set $A$ (kinetic parameters of chemical reactions: $k_{01}, k_{02}, \mathrm{~m}^{3} / \mathrm{mol}$; $\left.E_{1}, E_{2}, \mathrm{~J} / \mathrm{mol}\right) ; R$ - universal gas constant, $\mathrm{J} / \mathrm{mol} \cdot \mathrm{K}$; 
$c_{p, \mathrm{~g}}, c_{p, \mathrm{x}}$ specific heat of the gas phase and chemisorbent, respectively, $\mathrm{J} ; \rho_{\mathrm{g}}, \rho_{x}$ gas density phase and chemisorbent, respectively, $\mathrm{kg} / \mathrm{m}^{3} ; \alpha$ is heat transfer coefficient, W/m $/ \mathrm{m}^{2} \mathrm{~K} h_{1}, h_{2}$ thermal effects of chemical reactions, $\mathrm{J} / \mathrm{mol}$ );

$\mathbf{f}(\cdot)=\left\{f_{i}(\cdot), i=\overline{1, n}\right\}$ nonlinear vector function twice continuously differentiable with respect to arguments $x, y$ and parameters $a$ and $d$.

Let us consider in more detail the arguments of the operator and their relationship. Part of the components of the $x$ coordinate can be represented in the form where $\bar{x}+\Delta x$ the specified load on the life support system, $\bar{x}$ is an indefinite alternating component, such that $\|\Delta x\|<\|\bar{x}\|$ or even $\|\Delta x\|<<\|\bar{x}\|$; the vector parameter $a$ can also be represented in the form $\bar{a}+\Delta a$ where $\bar{a}$ is the "exact" or given component, but $\Delta a$ depends on the random component $\Delta x$, changes in the environmental parameters of the pressurized habitable object (temperature, humidity, pressure, etc.) and sometimes on variations $\Delta d$ in the design parameters of the reactor $d=\bar{d}+\Delta d$. We will simplistically consider both $\Delta x$ and $\bar{x}$, and also $\Delta a$ and $\bar{a}, \Delta d$ and $\bar{d}$ linearly independent, and $x$ and $d$ are independent of each other (although $\Delta d$ can affect $\Delta a$ ), but $\Delta d$ exists only at the design stage, and $\Delta x$ and $\Delta a-$ throughout the life cycle of the life support system.

For the convenience of the presentation of the material, we combine the undefined parameters $\bar{x}+\Delta x$ and $\bar{a}+\Delta a$ into a vector from a limited numerical set $\Xi=\left\{\xi_{\rho}: \xi_{\rho}^{-} \leq \xi_{\rho} \leq \xi_{\rho}^{+}\right\}, \rho=\overline{1, n}_{\xi}$.
Earlier, we developed a mathematical model [24] that describes the dynamics of changes in the concentrations of $\mathrm{O}_{2}, \mathrm{CO}_{2}, \mathrm{H}_{2} \mathrm{O}$ and the temperature of the gas-air mixture at the outlet of a chemisorption reactor and in a pressurized habitable object. Using the developed mathematical model, we carried out a numerical study of the dynamics of the chemisorption process and the effect of the load and structural parameters of the reactor on the time $t_{\mathrm{pr}}$ of the protective action of the air regeneration system in the PHO. The ranges of variation and nominal values of operating and structural parameters of a chemisorption reactor in a numerical study of the dynamics of the life support system are presented in Table 1.

The analysis of the dependence of the protective time $t_{\mathrm{pr}}$ on the number of plates with chemisorbent $N$ (not shown in the figure) (dimensions of one plate: length $l=0.87$, width $b=0.58$, thickness of chemisorbent $\varphi=0.002 \mathrm{~m}$ ) for different respiratory load $g_{\text {ind }}^{\mathrm{CO}_{2}}$ of a group of people (4 people) in a pressurized habitable object, shows that it is almost linear in nature. So, with an increase in the number of plates by 3 times, the time $t_{\mathrm{pr}}$ of the protective action of the air regeneration system in the PHO (with a respiratory load $g_{\text {ind }}^{\mathrm{CO}_{2}}=16 \mathrm{dm}^{3} / \mathrm{s}$ ) increases on average by $\sim 90 \mathrm{~min}$, and with a constant number of plates $N=4$ and an increase in respiratory load $g_{\text {ind }}^{\mathrm{CO}_{2}}$ of 2.4 times the protective action time $t_{\text {pr }}$ decreases by $\sim 70 \mathrm{~min}$.

Figures $1 a$ and $1 b$ show graphs of the dependence of the protective action time $t_{\mathrm{pr}}$ on the number of people $n$ in the pressurized habitable object for various values of the number of plates mounted in the reactor (Fig. 1a) and the respiratory load of people (Fig. 1b).

Table 1

Initial data for computational experiments

Initial data

\begin{tabular}{|c|c|c|}
\hline Gas-breathing mixture consumption, $\mathrm{dm}^{3} / \mathrm{s}$ & \multicolumn{2}{|r|}{27} \\
\hline Volume $V_{\mathrm{ob}}$ PHO, $\mathrm{m}^{3}$ & \multicolumn{2}{|r|}{24} \\
\hline The thickness $\varphi$ of the regenerative product on one side of the plate, $\mathrm{m}$ & \multicolumn{2}{|r|}{0.002} \\
\hline$L / b$ ratio & \multicolumn{2}{|r|}{1.5} \\
\hline The distance $\gamma$ between the plates, $\mathrm{m}$ & \multicolumn{2}{|r|}{0.02} \\
\hline Variables & Ratings & Range \\
\hline The number of people in the shelter, $n$, people & 4 & $2 \leq n \leq 6$ \\
\hline The rate of carbon dioxide release by a person $g_{\text {ind }}^{\mathrm{CO}_{2}} \times 10^{3}, \mathrm{dm}^{3} / \mathrm{s}$ & 16 & $16 \leq \mathrm{g}_{\text {ind }}^{\mathrm{CO}_{2}} \leq 38$ \\
\hline The surface area of the mass exchange gas-respiratory mixture with chemisorbent, $\mathrm{m}^{2}$ & 4.0 & $1.65 \leq S \leq 7.70$ \\
\hline The number of plates $N$ regenerative product, pcs & 4 & $2 \leq N \leq 6$ \\
\hline
\end{tabular}




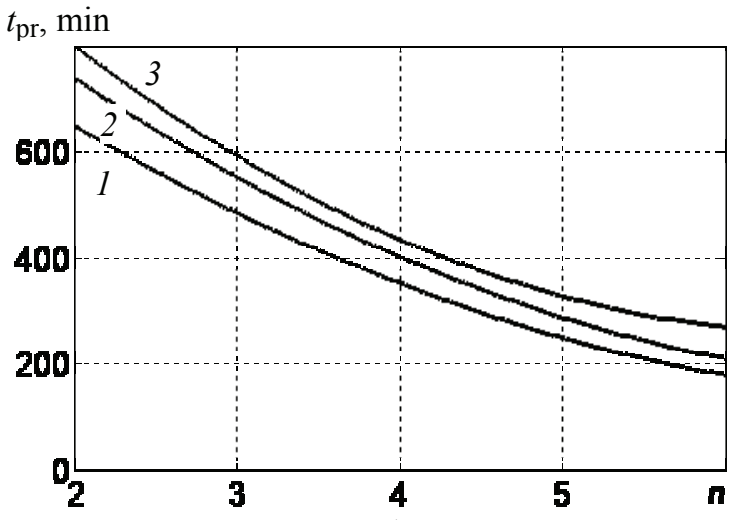

a) $t_{\mathrm{pr}}, \min$

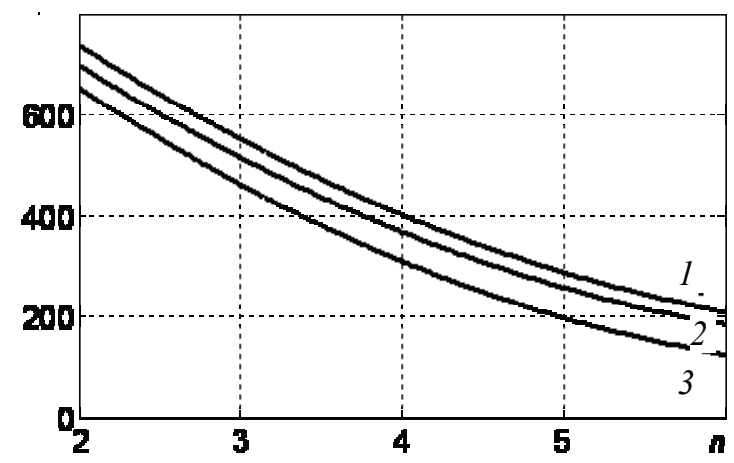

b)

Fig. 1. Dependences of the protective action time $t_{\mathrm{pr}}$ at $N=4$ from $n$ :

$a: 1-S=1.65 ; 2-S=4 ; 3-S=7.70, \mathrm{~m}^{2} ; b: 1-g_{\text {ind }}^{\mathrm{CO}_{2}}=16 ; 2-g_{\text {ind }}^{\mathrm{CO}_{2}}=27 ; 3-g_{\text {ind }}^{\mathrm{CO}_{2}}=38 \times 10^{-3} \mathrm{dm}^{3} / \mathrm{s}$

The analysis of the graphs shows that the time of the protective action of the air regeneration system in the PHO non-linearly depends on the number of people in the pressurized object and on their respiratory load. So from the graphs in Fig. $1 b$, it follows that with an increase in the group of people from 2 to 6 people, the time of the protective action of the air regeneration system in the PHO decreases by $\sim 3.35$ times.

Comparison of different breathing patterns of people in the PHO (normal $g_{\text {ind }}^{\mathrm{CO}_{2}}=16 \mathrm{~m}^{3} / \mathrm{s}$, with some excitement or light load $g_{\text {ind }}^{\mathrm{CO}_{2}}=27 \mathrm{~m}^{3} / \mathrm{s}$, under stressful conditions $g_{\text {ind }}^{\mathrm{CO}_{2}}=38 \mathrm{~m}^{3} / \mathrm{s}$ ) shows that the transition from normal breathing to breathing when stressful conditions (with a constant number of people (4 people)) leads to a twofold decrease in the time of the protective action of the air regeneration system of a PHO.

An analysis of the results obtained in the study of the functioning of the chemical air regeneration system made it possible to determine the areas of permissible modes of system functioning, as well as the maximum permissible values of the varied optimization parameters.

\section{Statement of the problem of optimal characteristics calculating of a chemical air regeneration system}

The task of calculating the optimal characteristics of a chemical air regeneration system contains the following components: objective function $I(u, \xi)$ (optimality criterion) - given time $t_{\mathrm{pr}}(u, \xi)$ of the protective action of the life support system; control variables $u$ is vector of design parameters of the chemisorption reactor (number of plates $N$ with chemisorbent, height $l$, width $b$, thickness $\varphi$ of chemisorbent and distance $\gamma$ between the plates); uncertain parameters $\xi$ is the magnitude of a person's respiratory load $g_{\text {ind }}^{\mathrm{O}_{2}}, g_{\text {ind }}^{\mathrm{CO}_{2}}$ and heat $Q_{\Sigma}$ (from people and devices), $\xi \in \Xi, \quad \Xi=\left\{\xi_{\psi}: \xi_{\psi}^{-} \leq \xi_{\psi} \leq \xi_{\psi}^{+}\right\}, \psi=\overline{1, f}_{\xi}$; communications in the form of equations of the mathematical model [24], which allow calculating the concentrations $\quad \bar{c}_{\mathrm{CO}_{2}}^{(j)}, \bar{c}_{\mathrm{O}_{2}}^{(j)}, \bar{c}_{\mathrm{H}_{2} \mathrm{O}}^{(j)}, j=1,2,3 \quad$ and temperature $T_{\mathrm{ob}}^{(j)}, j=1,2,3$ in a pressurized habitable object, as well as the values of the objective function the protective action time $t_{\mathrm{pr}}$ of the life support system; restrictions on the permissible content in the air of a sealed oxygen object $\mathrm{O}_{2}\left(\bar{c}_{\mathrm{O}_{2}}^{(2)}(u, \xi) \geq 19.0 \%\right.$ vol. $)$ and carbon dioxide $\mathrm{CO}_{2}\left(\bar{c}_{\mathrm{CO}_{2}}^{(2)}(u, \xi) \leq 1.0 \%\right.$ vol. $)$; as well as, actually, the mathematical formulation of the problem.

In addition to the input and output coordinates, the mathematical model of the dynamics of the process of chemical air regeneration includes indefinite (inaccurately specified) values of a person's respiratory load for oxygen $g_{\text {ind }}^{\mathrm{O}_{2}}$ and carbon dioxide $g_{\text {ind }}^{\mathrm{CO}_{2}}$, depending on his breathing mode, as well as the total heat $Q_{\Sigma}$ (from people and devices) in the PHO. Since it is not possible to determine the true values of these parameters at the design stage of the air regeneration system, in the best case they can be set by intervals of possible values, which also include the true values of these parameters.

In [24], as a criterion for solving the optimization problem, it was proposed to find the minimum protective action time $t_{\mathrm{pr}}$ (and, accordingly, the 
minimum dimensions of a chemisorption reactor) at which the restrictions on the concentration of oxygen and carbon dioxide in an airtight inhabited object are met. However, in the terms of reference for the development of a chemisorption rector, as a rule, the required time for its protective action is indicated $t_{\mathrm{pr}}^{\mathrm{t} \text {.t }}$.

Therefore, as a criterion for optimizing the design parameters of the air regeneration system under conditions of uncertainty, it is more correct to use the mathematical expectation $M_{\xi}\left\{\left(t_{\mathrm{pr}}(u, \xi)-t_{\mathrm{pr}}^{\mathrm{t} t \mathrm{t}}\right)^{2}\right\}$, since this indicator gives the average value of the deviation of the estimated time of the protective action $t_{\mathrm{pr}}(u, \xi)$ from the given one $t_{\mathrm{pr}}^{\mathrm{t} \text {. }}$.

We present a refined statement of the problem of calculating the optimal design parameters of a chemisorption reactor under conditions of uncertainty $\xi=\left\{g_{\text {ind }}^{\mathrm{O}_{2}}, g_{\text {ind }}^{\mathrm{CO}_{2}}, Q_{\Sigma}\right\}$ : for given values of the load on the life support system, it is necessary to determine the number and size of the chemisorbent layer $u^{*}=\left\{N^{*}, l^{*}, b^{*}, \gamma^{*}\right\}$ using a fixed depth $\varphi$ on one side of the plate, the protective action time $t_{\mathrm{pr}}$ of the life support system such that

$$
I\left(u^{*}\right)=\min _{u} M_{\xi}\left\{\left(t_{\mathrm{pr}}(u, \xi)-t_{\mathrm{pr}}^{\mathrm{t} . \mathrm{t}}\right)^{2}\right\},
$$

where $M_{\xi}\{\cdot\}$ the operation of "taking the mathematical expectation"; with connections in the form of equations of a mathematical model of the dynamics of the process of chemisorption [24] and restrictions:

- on the content of oxygen $\mathrm{O}_{2}$ and carbon dioxide $\mathrm{CO}_{2}$ in the $\mathrm{PHO}$ air:

$$
\begin{aligned}
& \max _{\xi \in \Xi}\left(g_{1}(y(u, \xi))=19.0-\bar{c}_{\mathrm{O}_{2}}^{(2)}(u, \xi)\right) \leq 0 ; \\
& \max _{\xi \in \Xi}\left(g_{2}(y(u, \xi))=\bar{c}_{\mathrm{CO}_{2}}^{(2)}(u, \xi)-1.0\right) \leq 0 ;
\end{aligned}
$$

- by the number $N$ and dimensions (height $l$, width $b$ of the plate and the distance $\gamma$ between the plates) of the chemisorbent plates

$$
N \leq N^{+}, l \leq l^{+}, b \leq b^{+}, \gamma \leq \gamma^{+} .
$$

Where $\mathrm{N}^{+}$- the maximum allowable number of plates with chemisorbent; $l^{+}, b^{+}, \gamma^{+}-$the maximum permissible values of the structural parameters of the regenerative cartridge of the chemisorption reactor.

The calculation of the multidimensional integral (1) was carried out according to an approximate formula

$$
I(u)=M_{\xi}\left(t_{\mathrm{pr}}(u, \xi)-t_{\mathrm{pr}}^{\mathrm{t} t \mathrm{t}}\right)^{2} \approx \sum_{j \in J_{1}} \omega_{j}\left(t_{\mathrm{pr}}\left(u, \xi^{j}\right)-t_{\mathrm{pr}}^{\mathrm{t.t}}\right)^{2},
$$

where $\omega_{j}$ is weighting coefficients satisfying the conditions $\omega_{j} \geq 0, \sum_{j \in J_{1}} \omega_{j}=1 ; \quad \xi^{j}\left(j \in J_{1}\right) \quad$ is approximation points uniformly covering the region of uncertainty $\Xi=\left\{\xi_{k}^{-} \leq \xi_{k} \leq \xi_{k}^{+}\right\}$.

\section{Calculation of optimal performance of chemical air recovery systems}

We show the algorithm for solving problem (1) (4) under conditions of uncertainty in the parameters of the respiratory load $g_{\text {ind }}^{\mathrm{O}_{2}}, g_{\text {ind }}^{\mathrm{CO}_{2}}$ a group of people, and heat $Q_{\Sigma}$ (from people and devices), i.e. $\xi=\left\{g_{\text {ind }}^{\mathrm{O}_{2}}, g_{\text {ind }}^{\mathrm{CO}_{2}}, Q_{\Sigma}\right\}$.

We introduce a priori the sets of approximation points $P_{1}=\left\{\xi^{j}: \xi^{j} \in \Xi, j \in J_{1}\right\}$ and "critical" points $P_{2}=\left\{\xi^{l}: \xi^{l} \in \Xi, l \in J_{2}\right\}$ at which the constraints of problem (2) - (3) can be violated.

Since the constraint functions (2), (3) are convex $g_{\lambda}(y(u, \xi)), \lambda=1,2$, it is advisable to include the corner points $\xi_{\psi}^{-}, \xi_{\psi}^{+}, k=\overline{1, f}_{\xi}$ in the initial set of critical points $P_{2}^{(0)}$ of the uncertainty region $\Xi \subset E^{f_{\xi}}$. We formulate the auxiliary problem (A): determine the minimum value of the function $I(u)$ and the vectors of design parameters $\hat{u}$ such that

$$
I(\hat{u})=\min _{u} \sum_{j \in J_{1}} \omega_{j}\left(t_{\mathrm{pr}}\left(u, \xi^{j}\right)-t_{\mathrm{pr}}^{\mathrm{t} . \mathrm{t}}\right)^{2}
$$

with connections in the form of equations of a mathematical model of the dynamics of the chemisorption process [24] and constraints (2) - (4): - at approximate points

$$
\begin{gathered}
g_{1}\left(y\left(u, \xi^{j}\right)\right)=\left(19.0-\bar{c}_{\mathrm{O}_{2}}^{(2)}\left(y\left(u, \xi^{j}\right)\right) \leq 0,\right. \\
g_{2}\left(y\left(u, \xi^{j}\right)=\left(\bar{c}_{\mathrm{CO}_{2}}^{(2)}\left(y\left(u, \xi^{j}\right)-1.0\right) \leq 0,\right.\right. \\
\xi^{j} \in P_{1}, \quad j \in J_{1} ; \\
- \text { at critical points } \\
g_{1}\left(y\left(u, \xi^{l}\right)\right)=\left(19.0-\bar{c}_{\mathrm{O}_{2}}^{(2)}\left(y\left(u, \xi^{l}\right)\right) \leq 0,\right. \\
g_{2}\left(y\left(u, \xi^{l}\right)=\left(\bar{c}_{\mathrm{CO}_{2}}^{(2)}\left(y\left(u, \xi^{l}\right)-1.0\right) \leq 0,\right.\right. \\
\xi^{l} \in P_{2}, \quad l \in J_{2} .
\end{gathered}
$$


Ranges of possible changes in the uncertain parameters

Table 2

\begin{tabular}{lcc}
\hline \multicolumn{1}{c}{ Uncertain parameters } & $\begin{array}{c}\text { Rated } \\
\text { value } \xi\end{array}$ & $\begin{array}{c}\text { Range of possible values } \\
\text { of undefined parameters } \xi\end{array}$ \\
\hline Respiratory load $g_{\text {ind }}^{\mathrm{O}_{2}} \times 10^{3}$, person in PHO, $\mathrm{dm}^{3} / \mathrm{s}$ & 141 & $83 \leq g_{\text {ind }}^{\mathrm{O}_{2}} \leq 200$ \\
The rate of carbon dioxide release by a person $g_{\text {ind }}^{\mathrm{CO}_{2}} \times 10^{3}, \mathrm{dm}^{3} / \mathrm{s}$ & 27 & $16 \leq g_{\text {ind }}^{\mathrm{CO}_{2} \leq 38}$ \\
Total heat dissipation $Q_{\Sigma}$ of a group of people and devices located in the PHO, W & 43 & $35 \leq Q_{\Sigma} \leq 51$ \\
\hline
\end{tabular}

The initial data for solving problem (1) - (4) are given in Table 1.

The ranges of possible changes in the uncertain parameters $\xi$ are presented in Table 2.

Since it is not known with what probability the uncertain parameters can take one or another value from the presented ranges in the Table 2 in a real process of chemical regeneration of air, we assume that the values of the uncertain parameters are equally probable. In this case, the coefficients $\omega_{j}$ will be the same for all approximation points, i.e. $\xi^{j}\left(j \in J_{1}\right)$, $\omega_{j}=1 / K_{J_{1}}, j=\overline{1, K_{J_{1}}}, j \in J_{1}$.

Next, we show an algorithm for solving problem (1) - (4) using the example of calculating the optimal characteristics of a chemical air-regeneration system for GOO. The block diagram of the algorithm is shown in Fig. 2.

\section{Algorithm}

Step 1 . We set the initial iteration numbers $k=1$, $v=1$ and the initial value of the number of plates $N^{(k=1)}=2$ with a chemisorbent thickness $\varphi=0.001 \mathrm{~m}$.

Step 2. We set the set of approximation points $\xi^{j}, j \in J_{1}, \xi^{j} \in P_{1}$, the initial set of critical points $P_{2}^{(v-1)}=\left\{\xi^{l}: \xi^{l} \in \Xi, l \in J_{2}^{(v-1)}\right\}, \quad$ and the initial approximations of the design parameters $u^{(k)}: l^{(k)}=0.8$, $b^{(k)}=0.8, \gamma^{(k)}=0.04$.

Each interval for changing the uncertain parameters $\xi$ (Table 2) consists of five approximation points $\xi^{j}: j=\overline{1,5} \quad g_{\text {ind }}^{\mathrm{O}_{2}}=\{83,112.25,141.5,170.75$, $200\}, g_{\text {ind }}^{\mathrm{CO}_{2}}=\{16,21.5,27,32.5,38\}, Q_{\Sigma}=\{35,39$, $43,47,51\}$. As the initial set of critical points $P_{2}^{(k)}$ at which the restrictions can be violated, we choose the corner points of the region (interval boundaries) $\Xi:=\{83,200\} ; g_{\text {ind }}^{\mathrm{CO}_{2}}=\{16,38\}, Q_{\Sigma}=\{35,51\}$.
Step 3. We find the solution of auxiliary problem (A) by the method of sequential quadratic programming $[39,40]$.

Next, we check the fulfillment of the conditions:

1) if $I(\hat{u})>10^{-3}$ hours and $N^{(k)}<N^{+}$then increase the number of plates $N^{(k+1)}=N^{(k)}+1$ and, assuming $k=k+1, v=1$, go to step 2;

2) if $I(\hat{u})>10^{-3}$ hours and $N^{(k)}=N^{+}$, then the algorithm finishes its work and the solution of problem (1) - (4) under these restrictions cannot be obtained;

3) if $I(\hat{u}) \leq 10^{-3}$ hours and $N^{(k)} \leq N^{+}$then go to the next step.

Next, we present the results of solving auxiliary problem (A) for iterations $k=1,2,3,4$ :

$$
I(\hat{u})^{(k=1)}=0.493,
$$

$\hat{u}^{(k=1)}=\left\{N^{(k=1)}=2, l^{(k=1)}=0.8, b^{(k=1)}=0.8, \gamma^{(k=1)}=0.04\right\}$,

$$
\begin{gathered}
I(\hat{u})^{(k=1)}>10^{-3} ; \\
I(\hat{u})^{(k=2)}>10^{-3}=0.084, \\
\hat{u}^{(k=2)=\left\{N^{(k=2)}=3, l^{(k=2)}=0.8, b^{(k=2)}=0.8, \gamma^{(k=2)}=0.04\right\},} \\
I(\hat{u})^{(k=2)}>10^{-3} ; \\
I(\hat{u})^{(k=3)}=0.012,
\end{gathered}
$$$$
\hat{u}^{(k=3)}=\left\{N^{(k=3)}=4, l^{(k=3)}=0.8, b^{(k=3)}=0.8, \gamma^{(k=3)}=0.04\right\},
$$$$
I(\hat{u})^{(k=3)}>10^{-3} \text {; }
$$$$
I(\hat{u})^{(k=4)}=9 \cdot 10^{-4},
$$$$
\hat{u}^{(k=4)}=\left\{N^{(k=4)}=5, l^{(k=4)}=0.8, b^{(k=4)}=0.32, \gamma^{(k=4)}=0.03\right\},
$$$$
I(\hat{u})^{(k=4)}<10^{-3} .
$$ 


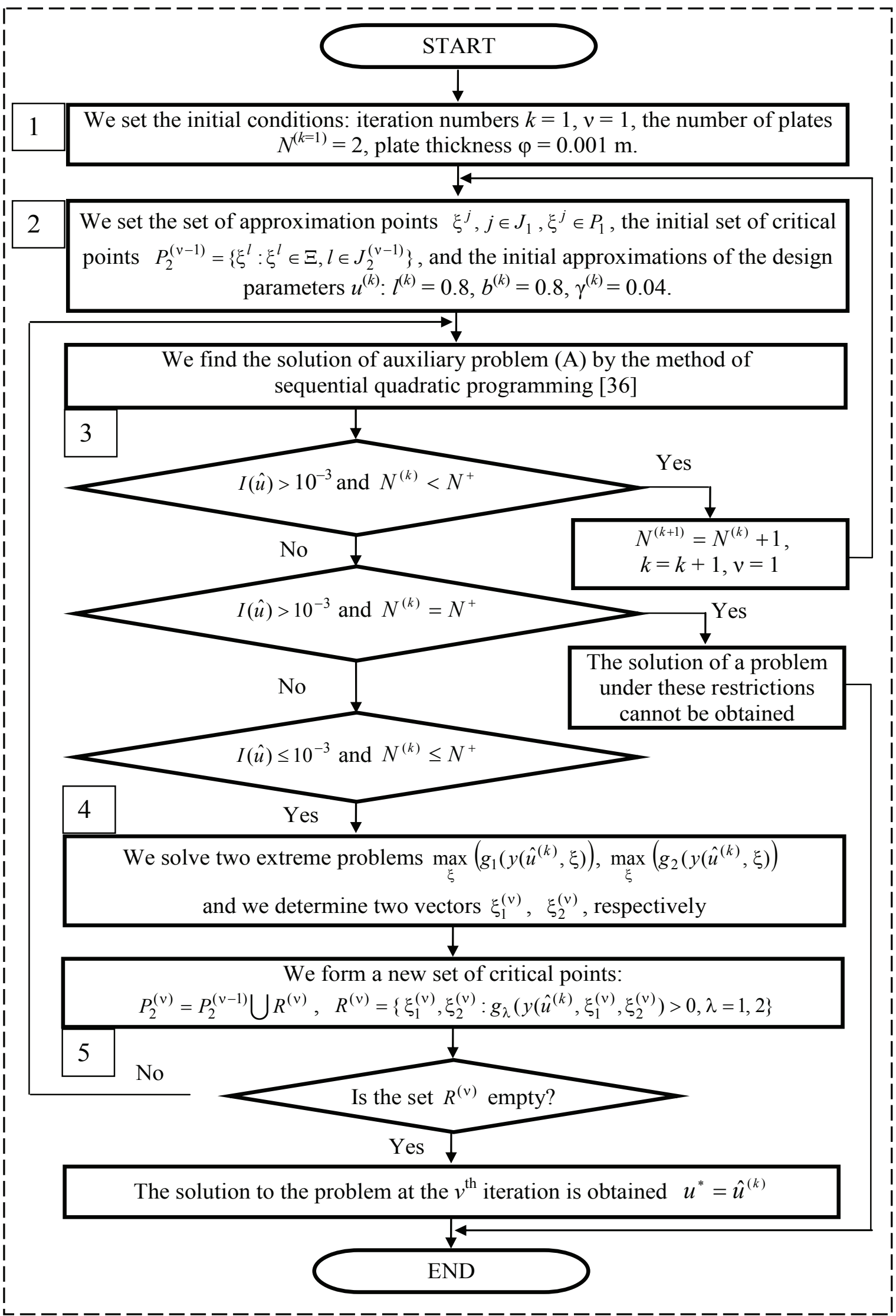

Fig. 2. The flowchart of the algorithm for calculating the optimal characteristics of a chemical air regeneration system under uncertainty 
Step 4. To determine new critical points, we solve two extremal problems $\max _{\xi}\left(g_{1}\left(y\left(\hat{u}^{(k)}, \xi\right)\right)\right.$, $\max _{\xi}\left(g_{2}\left(y\left(\hat{u}^{(k)}, \xi\right)\right)\right.$ and we determine two vectors $\xi_{1}^{(v)}, \xi_{2}^{(v)}$, delivering a maximum to the functions $g_{1}\left(y\left(\hat{u}^{(k)}, \xi\right)=\left(19.0-\bar{c}_{\mathrm{O}_{2}}^{(2)}\left(\hat{u}^{(k)}, \xi\right)\right)\right.$ and $g_{2}\left(y\left(\hat{u}^{(k)}, \xi\right)=\right.$ $=\left(\bar{c}_{\mathrm{CO}_{2}}^{(2)}\left(\hat{u}^{(k)}, \xi\right)-1.0\right)$, respectively.

We present the results of solving extremal problems for the case $k=4, v=1$ :

to limit $g_{1}$ :

$$
\xi_{1}^{(v=1)}=\left\{g_{\text {ind }}^{\mathrm{O}_{2}(v=1)}=200, g_{\text {ind }}^{\mathrm{CO}_{2}(v=1)}=38, Q_{\Sigma}^{(v=1)}=51\right\} ;
$$

to limit $g_{2}$ :

$$
\xi_{2}^{(v=1)}=\left\{g_{\text {ind }}^{\mathrm{O}_{2}(v=1)}=200, g_{\text {ind }}^{\mathrm{CO}_{2}(v=1)}=32, Q_{\Sigma}^{(v=1)}=51\right\} .
$$

Step 5. Verify that the constraints of the main problem (1) - (4) are fulfilled at the $v^{\text {th }}$ iteration $g_{\lambda}\left(y\left(\hat{u}^{(k)}, \xi_{1}^{(v)}, \xi_{2}^{(v)}\right) \leq 0, \lambda=1,2\right.$ and form a new set of critical points:

$$
\begin{gathered}
P_{2}^{(v)}=P_{2}^{(v-1)} \bigcup R^{(v)}, \\
R^{(v)}=\left\{\xi_{1}^{(v)}, \xi_{2}^{(v)}: g_{\lambda}\left(y\left(\hat{u}^{(k)}, \xi_{1}^{(v)}, \xi_{2}^{(v)}\right)>0, \lambda=1,2\right\} .\right.
\end{gathered}
$$

If the set $R^{(v)}$ is empty, then the solution to the problem at the $v^{\text {th }}$ iteration is obtained $u^{*}=\hat{u}^{(k)}$ and the algorithm finishes its work; otherwise, accept $v=v+1$ and go to step 3 .

We present the results of checking the fulfillment of the constraints of problem (1) - (4) at the iteration $k=4, v=1$ :

$$
\begin{gathered}
\left(19.0-\bar{c}_{\mathrm{O}_{2}}^{(2)}\left(\hat{u}^{(k=4)}, \xi_{1}^{(v=1)}\right)\right)=19.0-20.3=-1.3 ; \\
\left(\bar{c}_{\mathrm{CO}_{2}}^{(2)}\left(\hat{u}^{(k=4)}, \xi_{1}^{(v=1)}\right)-1.0\right)=0.85-1.0=-0.15 ; \\
\left(19.0-\bar{c}_{\mathrm{O}_{2}}^{(2)}\left(\hat{u}^{(k=4)}, \xi_{2}^{(v=1)}\right)\right)=19.0-20.3=-1.3 ; \\
\left(\bar{c}_{\mathrm{CO}_{2}}^{(2)}\left(\hat{u}^{(k=4)}, \xi_{2}^{(v=1)}\right)-1.0\right)=1.0-1.0=0 .
\end{gathered}
$$

Since $g_{1}\left(\hat{u}^{(k=4)}, \xi_{1}^{(v=1)}\right) \leq 0, \quad g_{1}\left(\hat{u}^{(k=4)}, \xi_{2}^{(v=1)}\right) \leq 0$, $g_{2}\left(\hat{u}^{(k=4)}, \xi_{1}^{(v=1)}\right) \leq 0, g_{2}\left(\hat{u}^{(k=4)}, \xi_{2}^{(v=1)}\right) \leq 0$, then the set $R^{(v=1)}$ is empty and in our case the algorithm finishes its work, the solution to problem (1) - (4) is obtained: $u^{*}=\hat{u}^{(k=4)}$ : number of plates $-N^{*}=5$ pcs; plate dimensions - length $l^{*}=0.8 \mathrm{~m}$, width $b^{*}=0.32 \mathrm{~m}$ and the distance between the plates $\gamma^{*}=0.03 \mathrm{~m}$.
At the same time, a guaranteed time $t_{\mathrm{pr}}^{\mathrm{t.t}}=5$ hours of protective action of the PHO chemical air regeneration system is achieved regardless of the possible change in the uncertain parameters within the specified limits (Table 2).

\section{Conclusions}

One of the significant results of this article is the development of a new approach in conditions of uncertainty of the respiratory load of people and the total heat release in an airtight habitable object to the calculation of the optimal characteristics of a chemical air regeneration system that provide the composition of the atmosphere (in terms of oxygen and carbon dioxide) in an airtight habitable object that is comfortable for breathing human level for a given time.

The developed algorithm can be used for the optimal design of new life support systems for people with guaranteed protective action time in the conditions of uncertainty of the initial data for design.

The authors are deeply grateful to Ph.D. Gladyshev N.F. and Ph.D. Gladysheva T.V. for a fruitful discussion of the problem statement and useful comments that contribute to improving the content of the article.

The work was financially supported by the Russian Ministry of Education and Science within the framework of project No. 10.3533.2017.

\section{References}

1. Wickham D.T., Gleason K.J., Engel J.R., Chullen C. Advanced Supported Liquid Membranes for Carbon Dioxide Control in Cabin Applications. Proceedings of 46th International Conference on Environmental Systems ICES-2016-77, Vienna, Austria, 2016.

2. Raatschen W. Advanced Life Support System for $\mathrm{CO}_{2}, \mathrm{H}_{2}, \mathrm{CO}, \mathrm{R} 134 \mathrm{a}$ and VOC Removal in Submarines. Proceedings of 47th International Conference on Environmental Systems ICES-2017-19, Charleston, South Carolina, 2017.

3. Gusenberg A.S., Zheleznyakov A.G., Romanov S.Yu., Telegin A.A., Yurgin A.V. Vybor kompleksa zhizneobespecheniya dlya ekipazhey dolgovremennykh kosmicheskikh stantsiy.[The choice of life support complex for the crews of long-term space stations]. Kosmicheskaya tekhnika i tekhnologii, 2015, 1 (8), pp. 67-80 (Rus).

4. Wickham D.T., Gleason K.J., Engel J.R., Cowley S. Advanced Supported Liquid Membranes for 
CO2 Control in EVA Applications. Proceedings of 43rd International Conference on Environmental Systems. ICES-2013, Vail, Colorado, 2013.

5. Proshkin V.Yu., Kurmazenko E.A., Kochetkov A.A., Gavrilov L.I. Voprosy ekspluatatsii regeneratsionnykh sistem obespecheniya gazovogo sostava Rossiyskogo modulya Mezhdunarodnoy kosmicheskoy stantsii [Issues of operating regeneration systems for providing gas composition to the Russian module of the International Space Station], Elektronnyy zhurnal "Trudy MAI", 2013, 65, 11. (Rus)

6. Gladysheva T.V., Gladyshev N.F., Dvoretsky S.I. Sistemy i sredstva regeneratsii i ochistki vozdukha obitayemykh germetichnykh ob"yektov [Systems and means of regeneration and air purification of inhabited pressurized objects], Moscow: Izd. dom "Spektr", 2016, 204 p. (Rus)

7. Qiu Z., Pang L., Li G., Zhang H. Numerical simulation of a cabin ventilation subsystem in a space station oriented real-time system. Chinese Journal of Aeronautics, 2017, 30 (6), 1809-1817.

8. Vilekar S.A., Hawley K., Junaedi C., Mansell J. Performance Evaluation of Staged Bosch Process for $\mathrm{CO}_{2}$ Reduction to Produce Life Support Consumables. Proceedings of 42nd International Conference on Environmental Systems ICES-2012, San Diego, California, 2012.

9. Wickham D.T., Gleason K.J., Engel J.R., Chullen C. Advanced supported liquid membranes for $\mathrm{CO}_{2}$ control in extravehicular activity applications. Proceedings of 43rd International Conference on Environmental Systems ICES-2013, Vail, Colorado, 2013.

10.Wang S., Jin L., Liu S., Zhang Z. Study on chemical oxygen source in underground emergency refuge system Study on integrated fire-fighting technology of fully-mechanized caving mining of the deeply inclined combustible thick seam Progress in Mine Safety Science and Engineering II. Proceedings of the 2nd International Symposium of Mine Safety Science and Engineering, 2014, 571-576.

11.Sharma G., Rai R.N. Reliability modeling and analysis of environmental control and life support systems of space stations: A literature survey. Acta Astronautica. 2019, 155, 238-246.

12.RPK-P TU 2123-232-05807954-2008. (Rus).

13. Kononov A.N. Sredstva regeneratsii, ochistki $i$ gazovogo kontrolya vozdukha [Means of regeneration, purification and gas control of air], Baku: KVVMU im. S.M. Kirova, 1981, 495 p. (Rus)

14.Gladysheva T.V., Gladyshev N.F., Dvoretskiy S.I. Nanokristallicheskiy produkt. Sintez. Svoystva.
Primeneniye. [Nanocrystalline product. Synthesis. Properties Application], Moscow: Spektr, 2014, 120 p. (Rus)

15.Putin S.B. Matematicheskoye modelirovaniye $i$ upravleniye protsessom regeneratsii vozdukha [Mathematical modeling and control of the process of air regeneration], M.: Mashinostroyeniye, 2008, 176 p. (Rus)

16.Marshall V. Osnovnyye opasnosti khimicheskikh proizvodstv [The main hazards of chemical industries], Moscow: Mir, 1989, 672 p. (Rus)

17.Strauss V. Promyshlennaya ochistka gazov. [Industrial gas cleaning], Moscow: Khimiya, 1981, 616 p. (Rus)

18.Li J., Jin L., Wang S., Zhang Z., Xu Y., Li Q. Experimental Study on Oxygen Supply Performance Influence Factors of Potassium Superoxide Oxygen Board Used in Confined Space. Advanced Materials Research, 2013, 726-731.

19.Gao N., Jin L., Hu H., Huang X., Zhou L., Fan L. Potassium superoxide oxygen generation rate and carbon dioxide absorption rate in coal mine refuge chambers. International Journal of Mining Science and Technology, 2015, 25(1), 151-155.

20.Xuan Y., Yu Q., Qin Q., Wang K., Duan W., Liu K., Zhang P. Selection of Desulfurizer and Control of Reaction Products on Flue-Gas Desulfurization Using Chemical-Looping Technology. Energy \& Fuels, 2018, 32 (1), 889-900.

21.Bokare A.D., Choi W. Singlet-Oxygen Generation in Alkaline Periodate Solution. Environmental Science \& Technology, 2015, 49 (24), 14392-14400.

22.Rodriguez-Mosqueda R., Bramer E., Brem G. $\mathrm{CO}_{2}$ Capture from Ambient Air Using Hydrated $\mathrm{Na}_{2} \mathrm{CO}_{3}$ Supported on Activated Carbon Honeycombs with Application to $\mathrm{CO}_{2}$ Enrichment in Greenhouses. Chemical Engineering Science, 2018, 189, 114-122.

23.Yao S., Zhang H., Chen Z. et al. Promotion of Graphitic Carbon Oxidation via Stimulating $\mathrm{CO}_{2}$ Desorption By Calcium Carbonate. Journal of Hazardous Materials, 2019, 363, 10-15.

24.Dvoretsky D.S., Dvoretsky S.I., Akulinin Ye.I. Modelirovaniye protsessa khimicheskoy regeneratsii vozdukha germetichnykh obitayemykh ob"yektov. [Modeling the process of chemical air regeneration of pressurized habitable objects]. Khimicheskaya fizika, 2017, 36 (7), 61-67. (Rus)

25. Balchanos M.G., Kwan H., Lu M., Patel A., Mavris D. Resilient Autonomous Systems: Metrics and Simulation-based Assessment and Life-Cycle Design Tools. AIAA Aerospace Sciences Meeting, 2018, 210059. 
26.Li Y., Lv M., Ling L., Yang L., Li D., Dong S. Analysis of Atmospheric Circulation for Physicochemical Regenerative Environment Control and Life Support System in Space Station. Proceedings of IEEE International Conference on Advanced Intelligent Mechatronics, AIM 2016, 7576981, 1491-1496.

27.Arai T., Fanchiang C., Aoki H., Newman D. Educational tool for modeling and simulation of a closed regenerative life support system. Acta Astronautica, 2008, 93, 1100-1105.

28.Lovelady E.M., Nworie G., Shirlberg N. Development of a Computer-Aided Tool for System Description, Modeling, Analysis and Integration for Screening Planetary Habitation Alternatives. Proceedings of 36th International Conference on Environmental Systems, ICES-2006, 2016, p. 90165.

29.Zhang X., Hoo K.A., Overland D. Modeling and Control Studies of an Integrated Biological Wastewater Treatment System. Proceedings of 35th International Conference on Environmental Systems, ICES-2005, 2005, p. 85861.

30.Cavazzoni J. Using explanatory crop models to develop simple tools for Advanced Life Support system studies. Advances in Space Research, 2004, 34, 1528-1538.

31.Anderson M. Modeling Integrated Air Revitalization Subsystems in Aspen Custom Modeler. Proceedings of 33rd International Conference on Environmental Systems, ICES-2003, 2003, p. 85859.

32.Fan X.-R., Wang X., Kang M., Hua J., Guo S., de Reffye P., Hu B.-G. A knowledge-and-data-driven modeling approach for simulating plant growth and the dynamics of $\mathrm{CO}_{2} / \mathrm{O}_{2}$ concentrations in a closed system of plants and humans by integrating mechanistic and empirical models. Computers and Electronics in Agriculture. 2018, 148, 280-290.

33.Manders E.-J., Bell S., Biswas G. Multi-Scale Modeling of Advanced Life Support Systems. Proceedings of 35th International Conference on Environmental Systems, ICES 2005, 2005, p. 85861.

34.Aydogan S., Orcun S., Blau G., Pekny J., Applequist G., Yih Y., Chiu G., Yao B. Aggregate
System Level Material Analysis for Advanced Life Support Systems. Proceedings of 33rd International Conference on Environmental Systems, ICES 2003, 2003, p. 85859.

35.Xing-Rong F., Xiujuan W., Jing H., Haoyu W., Mengzhen K. Proceedings-2017 Chinese Automation Congress, CAC 2017, 2017, pp. 7693-7698.

36.Akulinin E.I., Dvoretzkiy D.S., Dvoretsky S.I., Tugolukov E.N. Modelirovaniye protsessa obogashcheniya vozdukha kislorodom putem pogloshcheniya azota $\mathrm{v}$ ustanovke korotkotsiklovoy adsorbtsii [Modeling the process of air enrichment with oxygen by nitrogen uptake in a short-cycle adsorption unit], Vestnik Tambovskogo gosudarstvennogo tekhnicheskogo universiteta, 2012, 18(1),182-196. (Rus)

37.Akulinin E.I., Gladyshev N.F., Dvoretsky S.I. Perspektivnyye tekhnologii i metody sozdaniya kompozitsionnykh sorbtsionno-aktivnykh materialov dlya tsiklicheskikh adsorbtsionnykh protsessov [Promising technologies and methods for creating composite sorption-active materials for cyclic adsorption processes], Vestnik Tambovskogo gosudarstvennogo tekhnicheskogo universiteta, 2017, 23(1), 85-103. (Rus)

38.Akulinin E.I., Dvoretzkiy D.S., Dvoretsky S.I. Dinamika tsiklicheskikh adsorbtsionnykh protsessov obogashcheniya vozdukha kislorodom: modelirovaniye i optimizatsiya Dynamics of cyclic adsorption processes of air enrichment with oxygen: modeling and optimization, Vestnik tekhnologicheskogo universiteta, 2016, 19(17),108-114. (Rus)

39.Goldstein A.L. Optimizatsiya v srede MATLAB. Optimization in MATLAB, Perm': Izd-vo Perm. nats. issled. politekhn. un-ta, 2015,192 p. (Rus)

40. Ermakov A.A., Ivanov O.O., Akulinin E.I. Komp'yuternoye modelirovaniye protsessov $i$ apparatov pishchevoy, bio- $i$ khimicheskoy tekhnologii v srede flexpde [Computer simulation of processes and apparatuses of food, bio- and chemical technology in flexpde environment], Ucheb. posobiye, Tambov: Izd-vo GOU VPO “TGTU”, 2006, 70 p. (Rus) 